\title{
El cuerpo grotesco en EI Sexto, de José María Arguedas, y el personaje japonés en las fronteras del proyecto nacional ${ }^{1}$
}

\section{Ignacio López-Calvo}

University of California, Merced

lopezcalvo@msn.com

\section{RESUMEN}

Al igual que en el resto de la obra de Arguedas, en $E I$ Sexto todo lo malvado y vil se asocia con la vida urbana y criolla de la costa, mientras que la población y los motivos andinos y quechuas de la provincia reciben una caracterización mucho más posible. Pero en esta novela, junto con el mundo afroperuano, aparece una cuarta cultura que se ve representada en la novela, añadiendo leña a una heterogeneidad ya de por sí «incómoda»: existe un personaje japonés que al parecer fue arrestado por vagabundeo a quien los otros presos Ilaman Hirohito. Arguedas elige el cronotopo de la cárcel para explorar las paradojas y dilemas de la nación peruana. Por medio de una alegoría nacional, este espacio se une con el tiempo de la acción para convertirse en el centro organizador del argumento, un laboratorio en el que los personajes tratan sin éxito de resolver los problemas de las relaciones sociales y las contradicciones sociopolíticas en Perú. El comportamiento grotesco de Hirohito, junto con los comentarios que los otros presos hacen sobre él, lo retratan como un indeseado extranjero infiltrado en el seno de la nación. Por tanto, si bien El Sexto tiene el mérito de ser una de las primeras novelas peruanas en incluir un personaje de origen japonés, se lo incorpora por medio del prisma de lo grotesco, lo que produce una extraña distorsión del elemento japonés en la cultura peruana. El personaje sitúa a su grupo étnico en las afueras de la peruanidad, como si fuera una frontera humana, el Otro contra el que se construyen y actúan las contradicciones de la nación peruana.

1 Este artículo se publicó previamente en la revista académica Chasqui. 


\section{PALABRAS CLAVE}

Arguedas, El Sexto, japoneses, grotesco, proyecto nacional.

\section{ABSTRACT}

As is common in José María Arguedas's opus, in his third novel, El Sexto (1961), everything that is evil and vile is associated with the urban, coastal, and Criollo life, while the provincial, Andean, and Quechua population and motifs enjoy a much more positive image. But in this novel, together with the Afro-Peruvian world, there is fourth culture that is prominently represented in the novel, adding fuel to an already "uncomfortable" heterogeneity: we have an added element in a character of Japanese origin who was apparently imprisoned for vagrancy and whom other inmates call Hirohito. Arguedas chooses a specific chronotope to explore the paradoxes and dilemmas of Peruvian nationhood: the penitentiary. Through a national allegory, this overcrowded space merges with the time of the action to become the organizing center of the plot, a laboratory in which characters unsuccessfully try to resolve Peru's cultural relations and sociopolitical contradictions. Hirohito's grotesque behavior, as well as the comments that other inmates make about him portray him as a foreign alien who has eerily infiltrated the boundaries of the Peruvian nation. Therefore, even though El Sexto has the merit of being one of the first Peruvian novels to include a character of Japanese origin, this element of Peruvian nationality and culture is incorporated through the prism of the grotesque, which produces a bizarre distortion of the Japanese element in Peruvian culture. Arguedas's character situates the ethnic group he represents at the outskirts of Peruvianness, as if he were a a sort of human border, the Other against which all the contradictions of Peruvian nationhood are performed and constructed.

\section{KEY WORDS}

Arguedas, El Sexto, Japanese, grotesque, national project. 
No, no hay país más diverso, más múltiple en variedad terrena y humana; todos los grados de calor y color, de amor y odio, de urdimbres y sutilezas, de símbolos utilizados e inspiradores.

Arguedas, «No soy un aculturado»

Como es común en la obra de José María Arguedas (1911-1969), en su tercera novela, El Sexto (1961), todo lo que es malo y vil se asocia con la realidad urbana, costeña y criolla (o misti, para usar el término quechua para los criollos), mientras que las imágenes de la población y motivos provincianos, andinos y quechuas tienen connotaciones indudablemente más positivas ${ }^{2}$. Aun cuando la trama no tiene lugar en el Altiplano, la novela se ha interpretado con frecuencia como un ejemplo más del choque entre estas dos cosmovisiones y culturas aparentemente incompatibles. De hecho, varios diálogos parecen apoyar este enfoque. Así, cuando un preso llamado Pedro argumenta que no existen diferencias entre él y el minero Alejandro Cámac (un comunista en estado terminal que es el compañero de celda del protagonista), un indígena aprista de Arequipa llamado Mok'ontullo reacciona diciéndole que eso es imposible, porque Cámac es un indio.

Mario Vargas Llosa es uno de los críticos que apoyan esta perspectiva: «En realidad, la prisión es el decorado que usa Arguedas para representar, igual que en Los ríos profundos, un drama que lo hostigó toda su vida, el de la marginalidad, y para soñar desde allí con una sociedad alternativa, mítica, de filiación andina y antiquísima historia, incontaminada de los vicios y crueldades que afean la realidad en que vive» (Vargas Llosa 1996: 212). Vargas Llosa considera la novela de Arguedas la mejor articulación de lo que él considera «la utopía arcaica», es decir, una expresión del andinismo y el inmovilismo social; en otras palabras, un rechazo a la modernidad y a la sociedad industrial. Ciro A. Sandoval y Sandra M. Boschetto-Sandoval también han analizado el esquema anticolonización y el «paradigma de reivindicación cultural» presentes en El Sexto.

2 José María Arguedas Altamirano nació en la provincia de Andahuaylas, en el sur de los Andes peruanos. Aunque era mestizo, creció en una comunidad quechua. Se dice que aprendió a hablar quechua antes que el castellano, pero solo parte de su obra poética se publicó en quechua. Se sabe, igualmente, que escribía su poesía en quechua antes de traducirla al castellano. Arguedas escribió el resto de su poesía, sus novelas y sus textos autobiográficos en castellano. Junto con Ciro Alegría y Manuel Scorza, se considera a Arguedas uno de los tres grandes escritores indigenistas de Perú. Escribió numerosos estudios antropológicos, las colecciones de cuentos Agua. Los escoleros. Warma Suyay (1935), Amor mundo y todos los cuentos (1967) y Cuentos olvidados (1973); las novelas Yawar fiesta (1941), Diamantes y pedernales (1954), Los ríos profundos (1958), Todas las sangres (1964) y El zorro de arriba y el zorro de abajo (1971); y los poemarios Túpac Amaru Kamaq taytanchisman. Haylli-taki. A nuestro padre creador Túpac Amaru (1962), Oda al jet (1966), Qollana Vietnam Llaqtaman / Al pueblo excelso de Vietnam (1969) y Katatay y otros poemas. Huc jayllikunapas (1972). Con El Sexto, Arguedas ganó en 1962, por segunda vez, el Premio Nacional de Fomento a la Cultura Ricardo Palma. 
Sin embargo, se ha prestado poca atención a otros agentes importantes en estas estrategias de poder. En lo que supone una inversión de lo que ocurre fuera de la cárcel, varios presos afroperuanos (negros y zambos) están entre los más poderosos del presidio. Por el mismo camino, hay una cuarta cultura que queda representada de manera prominente en la novela, con lo que se añade combustible a una ya «incómoda» heterogeneidad: tenemos un elemento añadido en un personaje anónimo de origen japonés que parece haber sido encarcelado por vagancia (al igual que otro vagabundo en la prisión, el Pianista) y al que un preso afroperuano conocido como Puñalada llama despectivamente Hirohito ${ }^{3}$. De este modo, aun si se trata, como han señalado varios críticos, una de las obras menores de Arguedas, El Sexto tiene el mérito de ser una de las primeras novelas peruanas en incorporar un personaje japonés (o quizá nipoperuano $)^{4}$.

Si bien Cámac condena la degeneración moral que permea a la sociedad capitalina («La corrupción hierve en Lima — dijo [Cámac] — porque es caliente; es pueblo grande» [33]), el nivel de depravación en la prisión de El Sexto es aun mayor. De hecho, Arguedas elige un cronotopo específico para explorar las paradojas y dilemas de la nación peruana: el penitenciario. La mayoría de los eventos narrativos de la novela quedan subordinados a su sofocante atmósfera y a sus reducidas relaciones espaciales. Del mismo modo, la conexión intrínseca entre las categorías espaciales y temporales recontextualiza los puntos de vista y las ideologías de cada uno de los grupos en El Sexto. Por medio de una alegoría nacional, este espacio abarrotado confluye con el tiempo de la acción para convertirse en el centro organizador del argumento, un laboratorio en el que los personajes tratan sin éxito alguno de resolver las contradicciones sociopolíticas y las relaciones interculturales en Perú. El entorno carcelario de El Sexto fuerza toda una serie de interacciones sociales, intercambios culturales y luchas de poder que se hacen eco de los que tienen lugar, a mayor escala, en el resto del país. Allí se negocian asuntos relacionados con

\footnotetext{
3 Además del japonés, parece haber un preso chino, uno de los matones de Maraví, en la cárcel. Aunque en Latinoamérica el apodo el Chino no garantiza necesariamente un origen chino (después de todo, se conoce al expresidente nikkei Alberto Fujimori como el Chino), el hecho de que las palabras «el chino» no se escriban con mayúscula en la novela sugiere que se trata de veras de un hombre chino o sinoperuano. No obstante, en otras escenas se describe a este mismo personaje como «un hombre achinado» (31). Este personaje está a cargo de vigilar a Clavel, el niño indígena del que se abusa sexualmente, y de seguirlo las pocas veces que se le permite salir de la cárcel. El Chino también golpea al Pianista en otra escena.

4 Junto con Sara Castro-Klarén y Alberto Moreiras, Phyllis Rodríguez-Peralta también ha señalado las limitaciones estéticas de la novela: «In El Sexto Arguedas tried to paint a humanity capable of triumphing over sur-rounding brutality. Unfortunately, faceless prisoners, the constant cacophony of political dissension, and the obvious division of art and politics lessen his success» (227).
} 
la afiliación política, la clase, el nivel educativo, la etnia, la nacionalidad y la preferencia sexual, que a veces aparecen mezclados en un discurso teleológico de pertenencia o no a la nación peruana. Las cosmovisiones andina y criolla no son las únicas que colisionan y se ven obligadas a redefinir sus respectivas reivindicaciones con respecto a la peruanidad; varios hombres de descendencia africana se ven también forzados a coexistir con otros presos de origen indígena (indios y «cholos») y criollo, al igual que les ocurre a los presos comunistas y apristas, a idealistas instruidos y miembros de las masas iletradas, a militares y civiles $u$ a homosexuales y heterosexuales. Mientras que en condiciones normales los comunistas y apristas, por ejemplo, se habrían evitado mutuamente fuera del presidio, e Hirohito quizá se habría visto separado de los peruanos que no son de origen japonés por el mostrador de una bodega o de una peluquería, en la cárcel (otra heterotopía de desviación), este último no tiene dónde esconderse; no existe otro miembro de su comunidad étnica que pueda ofrecerle protección. Le guste o no, el personaje japonés, como el resto de los presos, tiene que compartir un espacio común, interpretar su papel teatral y sufrir sus consecuencias mortales.

Esta confusión de elementos dispares de la sociedad provoca situaciones grotescas. En este contexto, en su estudio de las bases de lo grotesco, Galt Harpham afirma: «In all the examples I have been considering, the sense of grotesque arises with the perception that something is illegitimately in something else. The most mundane of figures, this metaphor of co-presence, also harbors the essence of the grotesque in the sense that things that should be kept apart are fused together» (13). Desde esta perspectiva, el comportamiento grotesco de Hirohito, así como los comentarios que otros presos hacen sobre él, lo retratan como un elemento extranjero que ha infiltrado tenebrosamente las fronteras de la nación peruana. Aun cuando se podría argumentar que Gabriel, el protagonista de El Sexto, tampoco puede integrarse en una realidad violenta que no consigue comprender, al menos la considera su realidad y, por esta razón, se esfuerza para encontrar soluciones sociopolíticas. En contraste, en el caso de Hirohito su irredimible desarraigo impide que se le dé cabida en las narrativas de la nación peruana sinecdóquicamente actuadas en la prisión. Este japonés no debería estar allí; su incapacidad para pasar desapercibido en la prisión lo hace aún más grotesco que el resto de sus compañeros. Además, la absoluta dislocación que ha alienado a Hirohito también parece antagonizar a otros personajes, quienes desconfían de todo lo que rodea al intruso: el atuendo militar que llevaba cuando llegó a la prisión, su sonrisa misteriosa y aparentemente falsa, su supuestamente simulada manera de andar e incluso las razones por las que no encuentra un lugar 
secreto para defecar. En otras palabras, en un submundo infernal de injusticia y barbarie, este sombrío personaje que camina torpemente junto a los muros de la prisión y apenas comprende el castellano representa el más obvio «otro», un punto de ambigüedad que algunos de sus compañeros de cárcel encuentran casi ofensivo. Su nivel de abyección es notable incluso entre los miembros más miserables y degradados de la sociedad precisamente porque no tiene cabida en la prisión ni, por lo tanto, en el imaginario nacional de Perú. Sin embargo, nunca queda claro si esta es en parte la razón por la que Puñalada, uno de los líderes de las pandillas en la prisión junto con Rosita y Maraví, siente la necesidad de torturarlo y martirizarlo hasta que pierde la razón.

Castro-Klarén y Madrid afirman que la obra de Arguedas «is anchored on the need and the search for self-definition» (141). Por esta razón, incorpora episodios de su propia vida, incluyendo su infancia. En efecto, entre noviembre de 1937 y octubre de 1938, durante la dictadura de Óscar Raimundo Benavides, Arguedas fue encarcelado en una prisión federal llamada El Sexto y situada en la avenida Alfonso Ugarte de Lima, por participar, junto con otros estudiantes universitarios, en una agresión física al general fascista italiano Camarotta, quien estaba por aquel entonces de visita en la Universidad de San Marcos. Esta experiencia acabaría por marcar la vida del autor. Según explica Vargas Llosa en La utopía arcaica, los indignantes actos de violencia que presenció en El Sexto contribuyeron «a agravar, con una pesada carga, la maltratada vida emocional de Arguedas, aguzando sus sentimientos de inseguridad y su patética identificación con los humildes y los indefensos» (110). Más tarde, Arguedas utilizó esta penosa experiencia como inspiración para su novela El Sexto, un testimonio ficcionalizado (o una «narrativa metatestimonial urgente» [699], como la llama Ciro Sandoval), en el cual encontramos en Hirohito a uno de los personajes secundarios de origen asiático más memorables de la literatura latinoamericana. La historia la cuenta, con una prosa directa y vacía de experimentación formal, el álter ego de Arguedas, un serrano de 21 años Ilamado Gabriel Osborno, quien asegura no estar afiliado a ningún partido político. Este protagonista autobiográfico describe a los peores tipos sociales, quienes son responsables de las numerosas atrocidades que se cometen con total impunidad en la prisión. Después de tanto sufrimiento, tortura y hambre, varios presos, incluyendo a Hirohito, van progresivamente perdiendo la razón.

El mismo Arguedas explica, en una carta que escribió al doctor Murra en 1960, los principales temas de su novela: «¿Puede usted imaginarse lo que significaría para mí ver cómo los asesinos violaban a los hombres hasta volverlos locos? Esa es la parte medular de mi novela. Pero también 
El Sexto era un prisión política y juzgo con la libertad que he sabido conservar a los líderes de los partidos aprista y comunista que conocí en El Sexto" (Arguedas 1998: 50). Igualmente, en una carta escrita en 1961 a su amigo John, denuncia el novelista:

Odio desde la infancia el poder fundado en la riqueza material. Y casi todos los que me rodean no persiguen otro fin más alto para sus vidas que ese miserable objetivo. Te parecerán ingenuas mis palabras, pero a ti se te puede hablar con ingenuidad. El Sexto y todos mis pocos relatos están plenos de odio a esta parte oscura del ser humano y de una fe absoluta en que podrá vencer el mal (Arguedas 1998: 65).

En efecto, si bien el narrador autobiográfico en primera persona y otros personajes idealistas nunca pierden su fe en la posibilidad de construir un Perú mejor para los más oprimidos y marginados de la sociedad, el desenlace de la historia, como la muerte de Hirohito y del compañero de celda del protagonista, es ciertamente pesimista. Incluso la valiosa libertad para hablar abiertamente de política de la que disfrutan los presos de El Sexto queda contrarrestada por su incapacidad para difundir sus ideas fuera de los muros de la prisión o a otros presos, ya que la mayoría ha perdido la razón o están demasiado deshumanizados como para que les importen esos asuntos.

Hirohito, un delgado preso japonés con una barba rala y una sonrisa humilde y permanente, es una de las víctimas de la brutalidad que reina incontrolada en El Sexto. Viste trapos sucios que se van deteriorando aún más a medida que avanza el relato, y vive en el patio del primer piso, que equivale al último círculo del infierno de Dante. Comparte este siniestro espacio con asesinos y vagos, a los que se considera la escoria de la sociedad. Dos de los presos más poderosos, Puñalada y Maraví, humillan constantemente a los vagos, usándolos como «paqueteros» que deben llevar sus heces a las letrinas. Estos dos jefes de pandilla y sus secuaces, Colao y Pate'Cabra, también violan a algunos de los presos, los golpean a placer y los privan de todo tipo de dignidad humana. De hecho, estos abusos parecen funcionar como válvula de escape y como una herramienta para demostrar su poder al resto de los presos. En particular, el sádico Puñalada alivia su frustración por no ser correspondido por Rosita, un preso homosexual y travestido, humillando constantemente a Hirohito. Además de patear al japonés en el estómago y el pecho hasta dejarlo inconsciente por reírse de Maraví, en algunas de las numerosas escenas escatológicas de la novela Puñalada hace que su víctima defeque mientras baila o camina, o le da patadas para que caiga en sus propias heces. Este último tiene tanto miedo que ni siquiera se atreve a doblar las rodillas cuando usa la letrina. Estas circunstancias inevitablemente aceleran el deterioro físico y 
mental del japonés, quien pasa el resto del tiempo sacándose pulgas de los sobacos para comérselas o arrojarlas al suelo.

Cámac expresa su compasión por los presos más humillados: «Aquí, en mi pecho, está brillando el amor a los obreros y a los pobrecitos oprimidos» (27). De manera similar, Gabriel lamenta la patética situación de tres presos: el sumiso Hirohito, el indefenso preso conocido como el Pianista, quien perdió la razón tras repetidas violaciones, y un niño indígena al que llaman Clavel, quien también se volvió demente luego de haber sido utilizado como esclavo sexual. Para describir su propia pena, Gabriel se fija en la cara de Hirohito, quien, a su juicio, «trascendía una tristeza que parecía venir de los confines del mundo, cuando Puñalada, a puntapiés, no le permitía defecar» (23). Con un enfoque neonaturalista, el narrador provee una descripción detallada, en la primera escena en que aparece el japonés, de cómo se quita los trapos para defecar lo más rápidamente posible, antes de que lo vean Puñalada o Maraví. Estas grotescas situaciones, junto con su miedo, también despiertan la curiosidad de otros presos, quienes se ríen y aplauden cuando Hirohito termina de hacer sus necesidades. La única reacción defensiva de este consiste en mostrar su aliviada sonrisa y, según el narrador, su felicidad. Nunca queda claro, no obstante, si su pasividad es una actuación calculadamente defensiva o bien una prueba más de su demencia. A partir de esta escena podemos concluir que, mientras que otros presos simplemente excluyen a Hirohito de la narrativa de la nación, Puñalada, al prohibirle aliviar sus necesidades primarias, parece ir más allá: prácticamente niega su derecho a existir. En este contexto, Mikhail Bakhtin, en Rabelais and His World, asocia esta función corporal tanto con la vida como con la muerte:

All these convexities and orifices have a common characteristic; it is within them that the confines between bodies and between the body and the world are overcome: there is an interchange and an interiorization. This is why the main events in the life of the grotesque body, the acts of the bodily drama, take place in this sphere. Eating, drinking, defecation and other elimination (sweating, blowing the nose, sneezing), as well as copulation, pregnancy, dismemberment, swallowing up by another body-all these acts are performed on the confines of the body and the outer world, or on the confines of the old and new body. In all these events the beginning and end of life are closely linked and interwoven (93).

Al final, la agonía del japonés lo convierte en una especie de mártir, como sugieren las palabras del narrador unas páginas más tarde: «En el japonés y el Pianista había algo de la santidad del cielo y de la madre tierra» (106). 
Como el protagonista de la novela de Augusto Higa La iluminación de Katzuo Nakamatsu, el personaje japonés de Arguedas se pasa el día caminando. Pegado a los muros de la prisión, se desplaza desde las letrinas a las esquinas, como si estuviera tratando de volver a su Japón natal. Pero más aún que su constante caminar y sacarse pulgas, uno de sus rasgos más destacados es su persistencia, como señala Gabriel: «No los machucaron, sin embargo, hasta formar una masa sin nombre, como a los otros. En el cuerpo del japonés se arrastraba el mundo, allí abajo; conservaba su forma, aun su energía. De los wáteres a los rincones, caminando, o apoyado en la estaca, llevaba un semblante que no muere» (106). Al contrario que el Pianista o los otros vagos, quienes se resignan a chupar las sobras del suelo o la sangre de las peleas, o que simplemente acaban por morir de hambre, Hirohito no duda de luchar tenazmente por tener acceso al hombre que reparte la comida cada día. En contraste con su dócil conformismo cuando Puñalada y otros lo humillan en las letrinas, cuando Hirohito se empeña en conseguir comida, aguanta los empujones, patadas y codazos de presos más fuertes que él y, cuando se le empuja hacia atrás, vuelve aunque tenga que meterse por debajo de las piernas de los otros. Estas escenas de resistencia lo separan claramente de las imágenes estereotípicas de docilidad asiática en las Américas. El hombre afroperuano que reparte la comida admira tanto la bravura de Hirohito que lo defiende de los otros e incluso deja caer comida adicional en las manos de este. No obstante, una vez que el japonés ha devorado su ración, los presos que no han logrado recibir comida alivian su envidia golpeándolo hasta que le hacen vomitar. De nuevo, su única reacción es protegerse el estómago y sonreír. Los prisioneros políticos sienten compasión por él y tratan de darle latas de comida, pero los otros presos se las roban en el mismo día. Al final, el día en que Hirohito no aparece a luchar por su ración de comida, todos se dan cuenta de que ha llegado a su fin.

Aunque nunca se nos explica si Hirohito nació en el Perú o no, en algunas escenas no parece comprender bien el castellano. Además, un preso llamado Prieto señala que «para maldita su suerte atravesó el Pacífico en busca del Perú ique era de oro hace 500 años!» (25). Junto a su condición de extranjero, el mero acto de cruzar el Pacífico 500 años más tarde de cuando tenía sentido, es decir, cuando Perú ya no estaba «hecho de oro», parece constituir el primer paso hacia su locura final. En cualquier caso, si de veras se trata de un nikkei peruano, otros personajes parecen concebirlo como si representara una verdadera frontera humana de la nación peruana. Por ejemplo, el narrador afirma: «Los vagos se fueron acercando a esa celda, aun el japonés vino corriendo, encorvado, rascándose los sobacos» (89, énfasis mío). Igualmente, cuando los presos se ponen a bailar, 
Hirohito se queda indiferente $y$, al parecer, alienado, en su propio mundo: «El japonés se quedaba solo, rascándose, apoyado en la estaca, sin comprender ni interesarse por el tumulto ni el baile» (180). Y para añadir una prueba más de su extrañeza y torpeza, quizá debido a su demencia, mientras que otros personajes temen al peligroso Maraví, Hirohito es el primero en reírse cuando lo ve caminando embriagado en uno de los pasillos. Seguidamente, Puñalada lo golpea tanto que morirá poco tiempo después.

Como se mencionó anteriormente, Hirohito come pulgas y defeca mientras baila. Es, sin duda alguna, un personaje grotesco y, como tal, es no solo una fuente tanto de afinidad como de antagonismo, sino también de ambivalencia y ambigüedad. Como explica Geoffrey Galt Harpham, «the grotesque is always a civil war of attraction/repulsion» (11). Es revelador el hecho de que, si bien Gabriel siente pena por este japonés al que describe como un «desperdicio humano» (24), también desconfía de él. En sus graves diálogos y discursos sobre Hirohito y los japoneses, negocia sus propios sentimientos de atracción y repulsa por lo desconocido. Así, compara la permanente sonrisa de Hirohito y su sucia cara con el anochecer rojo, inmenso y triste que ve desde su celda, que, según él, «despertaba sospechas irracionales» (23) cuando uno lo miraba directamente. Gabriel también especula sobre las motivaciones que tiene Hirohito para sonreír tanto y sospecha que pueda incluso estar fingiendo su torpe manera de caminar: «empezó a caminar con la torpeza, como fingida, con que solía andar. Avanzó sonriendo hacia quienes aplaudieron. Con esa sonrisa fija, humildísima, aplacaba a sus camaradas de prisión; aun, a veces, a Puñalada» (23). En ocasiones, el preso japonés consigue, en efecto, recibir la conmiseración de sus compañeros. Por ejemplo, en otra escena, Puñalada «sonrió tristemente» (64) como si de repente hubiera sentido compasión por el japonés, después de darle un terrón de azúcar para que las pulgas le supieran mejor. En cualquier caso, el gesto simbólico de darle un terrón de azúcar, algo que suele asociarse más bien con un premio a un animal, indirectamente degrada y animaliza al personaje japonés aún más que el hecho de comer pulgas. Otros presos parecen quedar igualmente perplejos ante el comportamiento de Hirohito. Debaten, por ejemplo, sobre las razones que tiene para no buscar un lugar diferente para defecar. Si bien Gabriel argumenta que va a la letrina como mecanismo de autodefensa, es decir, como una manera de complacer a Puñalada y a su pandilla, un preso llamado Prieto lo estereotipa argumentando que la «disciplina japonesa» de Hirohito le impide actuar de manera diferente. Finalmente, el aprista indígena Juan Mok'ontullo provee una tercera teoría al culpar al mismo Perú por esta estrambótica situación. 
La prisión de El Sexto es también un lugar de actuaciones cuasi teatrales, tanto voluntarias como forzadas, en el sentido metafórico así como en el literal. Mientras que se obliga a Hirohito a bailar o a moverse mientras defeca, Clavel tiene que llevar ropa de mujer y los labios pintados y, tras la muerte de Puñalada, algunos presos imitan su peculiar manera de gritar los nombres de los presos. Los prisioneros políticos también recuerdan la humillante y grotesca escena que tuvo lugar cuando Puñalada obligó al Pianista a «tocar el piano» en las costillas del japonés mientras que se había obligado a este a tumbarse en el suelo y defecar. Además de forzar a algunos presos a representar estas humillantes actuaciones, existen también actuaciones voluntarias de «hombría», como las demostraciones de poder de los jefes de las pandillas; o de «femineidad», como la manera que tiene Rosita de andar, vestirse y cocinar para su «marido», el Sargento; o de afiliación, como los himnos políticos que cantan los comunistas y los apristas.

Hirohito es también un actor inconsciente. En este experimento de construcción de la nación que tiene lugar entre los muros de la prisión, él representa el «otro» absoluto contra el que se debe concebir la nación. En medio de todos los sitios inestables de la nación construidos por las diferentes luchas de poder que tienen lugar, el japonés acaba personificando lo que con toda seguridad no es peruano. Los apristas, por ejemplo, tratan de expulsar a los comunistas del cuerpo de la nación acusándolos de vendepatrias, de vendidos a los soviéticos o de haber traicionado al Perú. Del mismo modo, los presos de origen indígena aseguran a los comunistas que nunca serán capaces de sentir el mundo con la misma intensidad que (e, implícitamente, de ser tan peruanos como) un hombre que ha crecido entre los espectaculares paisajes de los Andes y que ha experimentado el antiguo Perú. En contraste, Hirohito, con sus limitaciones lingüísticas y la infranqueable barrera de su fenotipo extranjero (casi «antiperuano»), nunca tiene el lujo de ser visto, en ningún momento del relato, como parte del cuerpo nacional. Nadie puede excluir a un individuo que, en primer lugar, nunca ha sido incluido en el discurso nacional o en las agendas políticas. Es simplemente un obstáculo incómodo que ha de ser eliminado o al menos ignorado, un forastero que no tiene cabida en ningún lugar y que no debería estar allí, en medio del complicado proyecto de construcción de la nación. Por si su extraño comportamiento y su aura misteriosa fueran poco, según Cámac llegó a la cárcel vestido con indumentaria militar. Curiosamente, este detalle es reminiscente de la moda japonesa que, como explica Seiichi Higashide en su testimonio Adiós to Tears, se convirtió en el «people's uniform incident» para el FBI. Debido a este «uniforme», Cámac ve en su muerte el fin del militarismo japonés, aun cuando fue una 
víctima inofensiva. Gabriel, sin embargo, rechaza estas acusaciones hostiles: «Hermano Cámac-le dije-. El militarismo japonés tiene su agregado en la embajada. Este "Hirohito" Ilevaba una representación más alta. Se levantará sin duda; no es mortal» (107). Cuando Cámac muere también poco después y llevan los dos cadáveres juntos a un camión, un militar especula sarcásticamente: «El japonés va'fregar al cholo en el camino. Esto' japonese' ni muerto son tranquilo» (138). En este ejemplo, por tanto, ya no se presenta a Hirohito como un peligro para la seguridad nacional, sino como una inoportuna molestia, como un estereotipo. En contraste, Gabriel se toma a Hirohito en serio y les dedica palabras solemnes tanto a él como a su pueblo, cuando se dirige al espíritu de su compañero de celda recién fallecido:

El japonés, ahora que no es ya sino espíritu, recordará los cantos amados de su pueblo, que es tan martirizado como el nuestro. Cantaréis juntos siempre porque a ti y a él los echarán a la fosa común; lanzarán tierra y piedra sobre ustedes, con desprecio. El Japón es un pueblo más grande que el nuestro; pero no lo dejes ir allá, lo volverían miserable otra vez (138-139).

Arguedas, por medio de su narrador, expresa su profunda compasión por el japonés, una de las víctimas inocentes de la barbarie de la prisión y, por ende, de Perú. En el discurso de Gabriel se percibe un sentimiento de fraternidad internacionalista hacia los japoneses, otra nación que ha padecido injusticias a manos de sus gobernantes. En vez de ver a Hirohito como un accidente en el camino de la construcción de la nación, elige establecer paralelismos entre la opresión de las masas desamparadas de ambos países. En cualquier caso, cabe señalar que, aunque la locura de Hirohito es probablemente el resultado de los constantes abusos sufridos en la prisión, no queda claro si su raza o etnia fueron un factor determinante en la manera que lo trataron, particularmente si se tiene en cuenta que se trata todavía peor al Pianista (un criollo) o a Clavel (un indígena), ambos violados en numerosas ocasiones ${ }^{5}$.

Ciertos pasajes de El Sexto dan muestra de la autoexploración de Arguedas, en particular cuando trata de comprender su país por medio de paralelismos entre la prisión y la sociedad peruana. Así, Cámac pregunta:

5 En la novela póstuma de Arguedas El zorro de arriba y el zorro de abajo, existe un breve ejemplo de xenofobia contra los japoneses: «La procesión se detuvo un instante frente al mausoleo de un antiguo comerciante japonés que había sido principal en el puerto cuando fue puerto algodonero. El mausoleo era tan nuevo como el arco y estaba frente a él, reluciendo. Moncada alcanzó allí a la multitud, pero cara el médano; dio media vuelta, militarmente, bajó su cruz, como si fuera una escopeta, la apuntó hacia el mausoleo:

—Japonés solito — dijo-. Forastero. ¡Te mato a ti, mato a todos!» (64). 
«¿Dónde está la diferencia entre el negocio de esos, de afuera, y de estos, aquí dentro?» (26). En la misma línea, cuando Alfonso Calderón le hace una pregunta sobre las experiencias que inspiraron El Sexto, Arguedas no solo describe la prisión como un microcosmos del país, sino que también expresa su convicción de que la vida urbana pervierte a los ciudadanos:

Encontré allí lo que los sociólogos llaman una «muestra completa» del Perú. Entre los 500 presos que estaban, desde los sujetos más pervertidos por la ciudad hasta los dirigentes y militantes políticos más puros, los más esclarecidos y serenos y los fanáticos, distribuidos en pisos libremente comunicados por escaleras. Vi allí también lo que aún seguiría llamando infernales escenas y conflictos sexuales (Arguedas 1996: 405).

En medio de los esfuerzos literarios de Arguedas para comprender la peruanidad y para reconciliar los mundos andino y criollo, encuentra un signo de interrogación en el personaje japonés, quien acaba por complicar aún más un situación ya de por sí enrevesada. ¿Cuál es el papel de Hirohito en el conflicto entre los dos Perú, el indígena y el criollo? Si es cierto que se puede concebir la prisión de El Sexto como un microcosmos de la injusticia y el ultraje que reina en el país en el momento en que Arguedas escribió la novela, se podría argüir también que este japonés anónimo y desventurado puede verse también como una sinécdoque del dilema de su comunidad. Más aún, los personajes andinos o serranos, quienes, como Arguedas y su álter ego protagonista, conciben la ciudad como la fuente de todas las impurezas y perversiones, encuentran en el japonés la más extrema extrañeza; como se señaló anteriormente, consideran su cara, su sonrisa, su atuendo, e incluso su manera de andar sospechosos. En este contexto, Anne-Marie Lee-Loy, refiriéndose a los chinos en la literatura de las Antillas de habla inglesa y a las narrativas que se usan en la articulación de la identidad nacional como «pertenencia», explica: «There is more than one way to imagine the boundaries of national belonging, and the fictional images of the Chinese capture this inherent instability» (4). A mi juicio, lo mismo puede afirmarse de la imagen del japonés en $E I$ Sexto. En esta «muestra» de la nación que encuentra Arguedas en la cárcel, Hirohito representa la liminalidad entre lo peruano y lo no peruano, la frontera humana de la nación. Es más, su aspecto y comportamiento misteriosos tipifican la naturaleza engañosa de todo lo urbano. Al igual que las aberraciones sexuales que tienen lugar en la prisión, el lastimoso comportamiento de Hirohito contribuye a justificar el ethos antiurbano de los serranos.

En esta novela, Arguedas muestra tener una fascinación neonaturalista con todo lo repugnante y opresivo que encuentra en la sociedad. 
Describe numerosas escenas grotescas que enfatizan las necesidades corporales primarias que tienen que ver con la comida, el sexo y la evacuación. Con respecto a la excreción, al principio del relato, por ejemplo, se nos cuenta que el alcaide ha ordenado a los soplones que cubran las bocas de los prisioneros políticos con las heces de los vagos. Además, los jefes de las pandillas ordenan a sus «paqueteros» que lleven sus excrementos, envueltos en periódicos, a las letrinas. Por lo que respecta a la alimentación, la comida de la prisión está podrida, Hirohito come pulgas y los vagos lamen el suelo en busca de sobras o de sangre, o comen basura y escupiduras de los que han tenido la suerte de comer algo. A su vez, las escenas sexuales reflejan exhibicionismo y violación individual o en grupo. Dentro de esta amplia muestra de escenas grotescas en la novela, Arguedas ha encontrado en Hirohito la personificación de lo estrafalario. Si bien los aspectos más grotescos relacionados con lo sexual quedan representados por otros personajes (el travestido Rosita, los violados Clavel y el Pianista o el vago afroperuano que muestra su inmenso pene por unos centavos), Hirohito es la pieza central en las escenas que tienen que ver con la evacuación o la alimentación grotescas. Es, de hecho, su resolución con llegar a la primera línea en las escenas de reparto de comida y con comer tan rápido como pueda, así como su obsesión con defecar sin ser descubierto por su némesis, Puñalada, lo que hace que este personaje secundario sea memorable. En último término, todas estas escenas degradantes unen inextricablemente la fisiología humana a los conflictos sociopolíticos y culturales. Los intercambios sociales y corporales se hacen inseparables: el deterioro progresivo y la muerte final del cuerpo grotesco auguran una degeneración similar en el campo de lo social.

En El Sexto, Arguedas exhibe una actitud aparentemente progresista en defensa del pueblo indígena y de un inocente miembro de un grupo minoritario, la comunidad nikkei. Sin embargo, estos pasajes quedan contrarrestados por la homofobia subconsciente y el tono un tanto racista que caracteriza el resto de la novela. Como indica Vargas Llosa en La utopía arcaica, Cámac parece haber convencido a Gabriel de que la homosexualidad jamás podría tener cabida en el mundo andino, pues se trata simplemente del resultado del vicio urbano: «Lo hubiéramos matado en su tiempo debido, si hubiera sido. Allá no nacen» (34), argumenta Cámac en El Sexto. Asimismo, continúa Vargas Llosa, Arguedas describe a los personajes negros y mulatos de manera muy negativa y ve también el mestizaje con sospecha:

El andinismo y el afán de conservar la tradición quechua en su mayor pureza generan el inconsciente racismo que informa la novela: la distribución de cualidades morales y espirituales según la condición 
étnica de las personas. Ya hemos visto que los serranos en la novela tienden a ser buenos, generosos y virtuosos, en tanto que los costeños, sobre todo si son negros o mulatos, se los diría condenados a la crueldad, codicia y corrupción. Lo que dicta esos sentimientos, más todavía que el prejuicio contra el hombre de color, es el sueño de la pureza étnica —otra pieza clave de la doctrina indigenista-, el oscuro temor de que la hibridación racial, el mestizaje, la confusión de razas, puedan destruir la integridad del pueblo quechua (Vargas Llosa 1996: 220).

Los comentarios de Vargas Llosa son reminiscentes de la notoria polémica entre Arguedas y otro escritor del boom, el cosmopolita Julio Cortázar. En su famosa «Carta a Roberto Fernández Retamar», que envió desde París en 1968, este último había condenado el excesivo nacionalismo y el telurismo provinciano de algunos escritores latinoamericanos. A su juicio, toda literatura concebida como exaltación de lo local o influenciada por una perspectiva etnológica o folclórica era un tipo de nacionalismo o incluso de racismo. Arguedas se sintió insultado por estos comentarios y respondió, también en una carta pública aparecida en la revista Amaru, defendiendo su literatura comprometida en defensa del indígena y burlándose del argumento del argentino con respecto a que un escritor podía descubrir las auténticas raíces de Latinoamérica mejor desde Europa que desde la posición provinciana del que nunca sale de su país. La polémica continuó más tarde en cartas enviadas a la revista Life, al periódico El Comercio e incluso en la novela póstuma e inconclusa de Arguedas EI zorro de arriba y el zorro de abajo (1969).

En conclusión, aun cuando El Sexto tiene el mérito de ser una de las primeras novelas peruanas en incluir a un personaje de origen japonés, este elemento de la nacionalidad y la cultura peruanas se incorpora por medio del prisma de lo grotesco. Inspirado en hechos reales, el personaje de Arguedas sitúa al grupo étnico que representa en las afueras de la peruanidad. Es una suerte de frontera humana, el «otro» contra el que se construyen y actúan todas las contradicciones de la nación peruana. La demencia y alienación de Hirohito, así como los repugnantes actos a los que se ve obligado a llevar a cabo, lo convierten en una fuente de risa y de pena para los otros presos. Su apariencia anamórfica, que provoca tanto simpatía como asco en los demás, se convierten en última instancia en una extraña distorsión del elemento japonés en la cultura peruana. 


\section{REFERENCIAS BIBLIOGRÁFICAS}

ARGUEDAS, José María (1998). Las cartas de Arguedas. Lima: Fondo Editorial de la Pontificia Universidad Católica del Perú.

(1969). El Sexto. Lima: Horizonte.

(1996). «No soy un aculturado». En El zorro de arriba y el zorro de abajo. Madrid: Allca XX y Fondo de Cultura Económica.

BAKHTIN, Mikhail M. (1984). Rabelais and His World. Bloomington, Indiana: Indiana University Press.

CASTRO-KLARÉN, Sara y MADRID, Arturo (1976). "Travels ("Los viajes", from Los ríos profundos of José María Arguedas)». En Latin American Literary Review, vol. 4, nro. 8, pp. 141-149.

GALT HARPHAM, Geoffrey (2006). On the Grotesque: Strategies of Contradiction in Art and Literature. Aurora, Colorado: The Davies Group Publishers.

HIGA, Augusto (2008). La iluminación de Katzuo Nakamatsu. Lima: San Marcos.

HIGASHIDE, Seiichi (2000). Adiós to Tears: The Memoirs of a Japanese-Peruvian Internee in U.S. Concentration Camps. Seattle: University of Washington Press.

LEE-LOY, Anne-Marie (2010). Searching for Mr. Chin. Constructions of Nation and the Chinese in West Indian Literature. Filadelfia: Temple University Press.

SANDOVAL, Ciro A. (1997). «El Sexto de José María Arguedas: espacio entrópico de hervores metatestimoniales». En Revista iberoamericana, nro. 181, pp. 697-709.

SANDOVAL, Ciro A. y BOSCHETTO-SANDOVAL, Sandra M. (1998). "José María Arguedas's El Sexto: The Gestation of an Andean Paradigm of Cultural Reivindication. En Ciro A. Sandoval y Sandra M. Boschetto-Sandoval (editores). José María Arguedas. Reconsiderations for Latin American Cultural Studies. Athens, Ohio: Ohio University Center for International Studies.

VARGAS LLOSA, Mario (1996). La utopía arcaica: José María Arguedas y las ficciones del indigenismo. México D. F.: Fondo de Cultura Económica de México. 